\title{
ARACHNOID CYST
}

\section{ADVERSITY ANS PLASTICITY}

\section{GUILHERME BORGES* HELDER JOSÉ LESSA ZAMBELLI**, YVENS BARBOSA FERNANDES **, EDMUR FRANCO CARELLI*, LEONARDO BONILHA***}

\begin{abstract}
We report four cases of surgically treated intracranial arachnoid cysts, one with cyst-peritoneal shunt and three with craniotomy and arachnoid membrane resection. Their classification and etiopathogeny are discussed, and especially the different methods of treatment comparing the drastic complications (adversities) with the favorable solutions in severe clinical cases (plasticity) treated at our institution.
\end{abstract}

KEY WORDS: arachnoid cyst, shunt, intracerebral hemorrhage, brain plasticity, craniotomy, endoscopy.

\section{Cisto aracnóideo: adversidade e plasticidade}

RESUMO - Apresentamos revisão da classificação dos cistos de aracnóide, etiopatogenia e diferentes formas de tratamento em relação às complicações drásticas (adversidade) e às soluções favoráveis (plasticidade) em casos graves, tratados na instituição de origem. Foram tratados quatro casos através de derivação cistoperitoneal ou craniotomia extensa com ressecção da membrana cística, sempre analisados de acordo com a gravidade dos sintomas, localização e extensão da lesão.

PALAVRAS-CHAVE: cisto aracnóideo, derivação, hemorragia intracerebral, plasticidade cerebral, craniotomia, endoscopia.

The arachnoid cyst consists of a fluid collection covered by a membrane similar to arachnoid, located between the arachnoid and the piamater ${ }^{1,2}$. The congenital arachnoid cyst or primary cyst should be differentiated from other congenital or acquired abnormalities which range from prosencephalic cyst, dilated cisterns, loculations of the subarachnoid space secondary to brain traumatism, hemorrhage or inflammatory processes ${ }^{2-8}$. The heterogeneous cysts are denominated secondary cysts. Arachnoid cysts represent approximately $1 \%$ of the intracranial expansive lesions ${ }^{9}$. The origin of the arachnoid cyst is probably related to an abnormal development of the arachnoid, which can divide or duplicate itself ${ }^{10,11}$. Structural features of the arachnoid cyst wall is different from the normal arachnoid membrane ${ }^{12}$. Its symptoms are very diverse, such as headaches, epilepsy, hydrocephaly, intracranial hypertension, macrocephaly, calvarium proeminence, cranial nerves palsies, vertigo, discrete proptosis, hemiparesis, mental retardation or even be asymptomatic. The arachnoid cyst of the middle fossa, the most frequent, is generally discovered in patients under the age of 20 , however, it can be found at any age ${ }^{9}$. It is much more common and also more frequent in diagnosed males on the left side. The clinical picture in elderly patients is similar to that of chronic subdural hematoma or normal pressure hydrocephalus, usually in form of dementia, hemiparesis, ataxia, bladder incontinence or gait disturbances ${ }^{13}$.

We present a review of the cysts classification, etiopathogeny, different methods of treatment in addition to the drastic complications (adversities) and the favorable solutions in severe clinical cases (plasticity), treated at the institution of origin.

Disciplina de Neurocirurgia da Faculdade de Ciências Médicas (FCM) da Universidade Estadual de Campinas (UNICAMP): *Professor Doutor; **Médico Contratado; ***Acadêmico. Aceite: 10-fevereiro-1999.

Dr.Guilherme Borges - Rua Barão Geraldo de Rezende 282/24 - 13020-440 Campinas SP-Brasil. E-mail:gborges@correionet.com.br 


\section{CASES}

Case 1. This 54-year-old man complained of a continuous, daily, left-sided headache in the last eight months. He also reported paresthesias on the left side of the body, more prominent on the arm. Two years before he fell in the bathroom and suffered head injury. The neurological examination was normal, except for a lack of venous pulse on ocular fundi. He had been operated on previously in another hospital for evacuation of a left huge temporal cyst (twist drill hole) with only temporary alleviation of the symptoms. The CT (computerized tomography) scan showed a large collection of fluid in the left Sylvian fissure, with midline shift and without enhancement with contrast media: the diagnosis was arachnoid cyst. The patient was operated on via a pterional approach, resection of the cyst wall and wide communication with the basal cistern. The fluid content was slightly xantochromic. The surgical procedure was uneventful, but postoperatively the patient developed arterial hypertension, seizures and coma. Immediately a CT scan showed an intracerebral hematoma in the insular region accompanied by a diffuse hemorrhage in the posterior fossa (including cerebellum and brainstem) and acute hydrocephalus. The patient was submitted to an external ventricular drainage, but died one week later. Pathological examination demonstrated a simple arachnoid cyst, with the presence of macrophage and hemosiderine staining in its capsule (Fig 1).

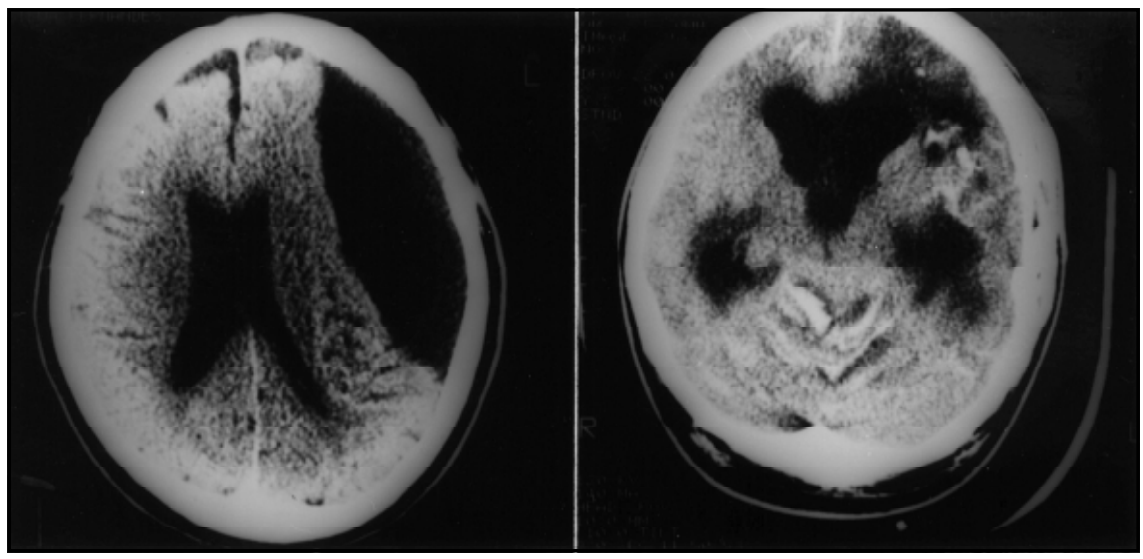

Fig 1. Left, CT scan : a large cyst in the left Sylvian fissure with midline shift. Right, post-operative CT shows a diffuse posterior fossa hemorrhage with acute hydrocephalus.
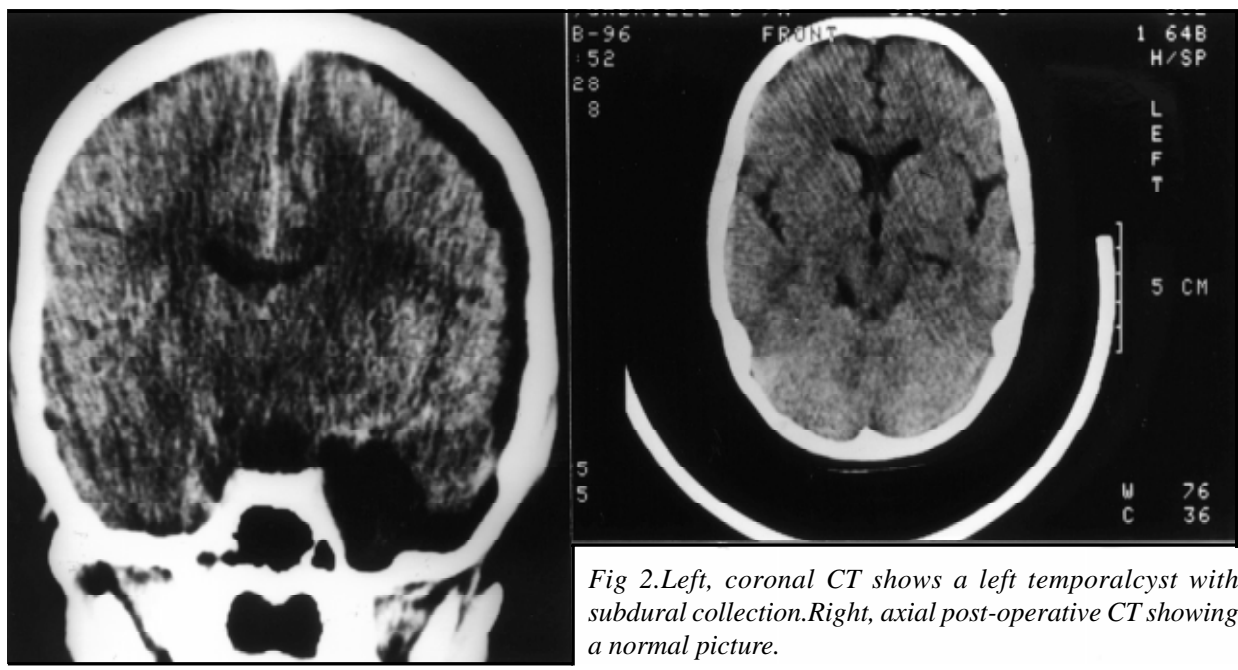

Fig 2.Left, coronal CT shows a left temporalcyst with subdural collection.Right, axial post-operative CT showing a normal picture. 


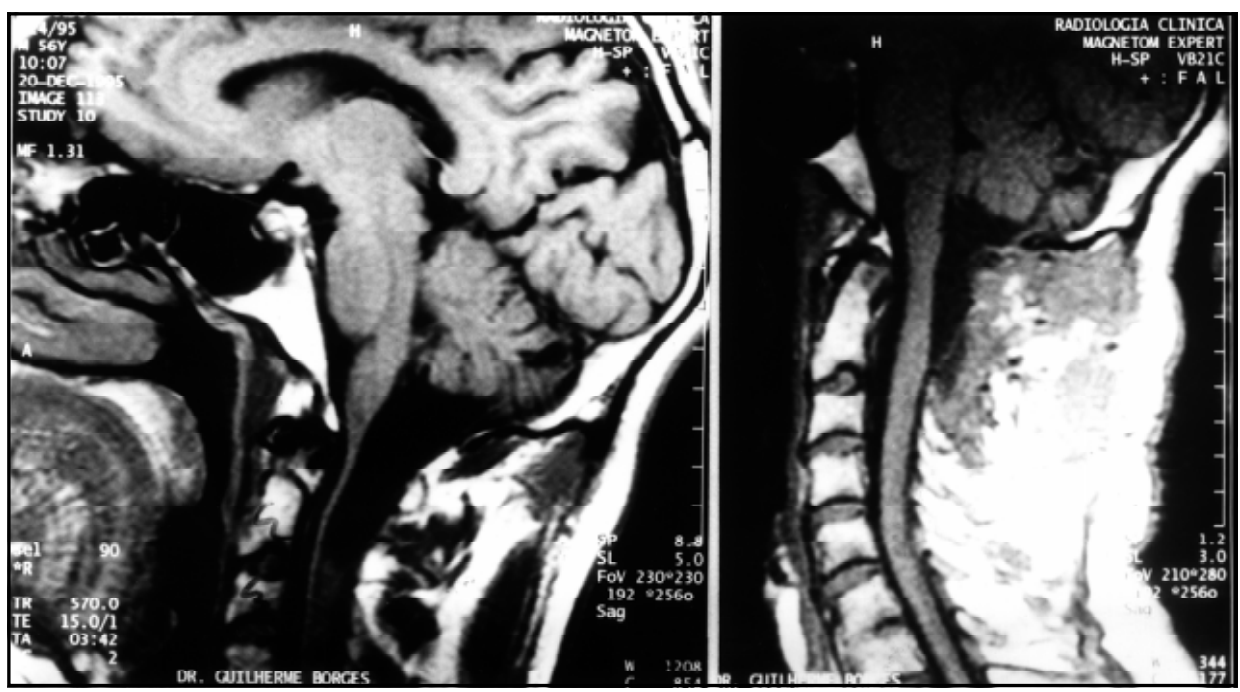

Fig 3. Left, sagittal T1-weighted MRI shows a large cyst in the posterior fossa with brainstem mass effect. Right, post-operative sagittal T1-weighted MRI showing a brainstem normal shape.

Case 2. This seven-year-old girl presented with a history of holocranium headache and diplopia in the last five days. Headache has begun soon after a head injury without loss of consciousness. The neurological examination showed bilateral papilledema and left sixth nerve palsy. CT scan demonstrated a cyst in the left temporal region with a subdural collection on the same side. Surgical treatment was done through a left parietal craniotomy, fenestration of the subarachnoid space and drainage of a great quantity of clear liquid under pressure. The postoperative course was uneventful, with left sixth nerve recovery (Fig 2).

Case 3. This 54-year-old man presented with a clinical history of progressive weakness and stiffness of his four limbs in the last three years. Previously he had been submitted to a cervical surgery to treat a C5-C6 disc protrusion, without amelioration. The neurological examination showed severe tetraparesis, spasticity, pyramidal signs and ataxia. MRI (magnetic resonance image) showed a large cyst in the posterior occipital-cervical transition, exerting a mass effect on the brainstem. The surgical procedure (in ventral position ) was done through a high cervical laminectomy extended to the posterior fossa, drainage of the cyst with fenestration of the subarachnoid space. The post-operative course was without abnormalities and the patient recovered from his deficits. A new MRI was performed and showed absence of cyst and a normal shape of the brainstem (Fig 3).

Case 4. This 15-year-old girl presented with a clinical picture of headache, nausea and vomiting for onea-half month. She also reported a light head injury two months before. The neurological examination disclosed only a slight disc blurring. CT scan showed a left temporal arachnoid cyst and a subdural collection on the same side. MRI showed a CSF (cerebrospinal fluid) subdural collection not due to an old traumatic bleeding (more frequent in these cases). It is supposed that the cyst wall ruptured during trauma, leading to the development of the subdural collection. She was submitted to a cyst-peritoneal shunt with a low-pressure valve. The post-operative course was uneventful (Fig 4).

\section{DISCUSSION}

The most appropriate therapeutics for treating arachnoid cyst still remains a matter of controversy. There seems to be a consensus favoring conservative treatment in asymptomatic cases $^{3,4,10,13-16}$. However it is known that in such cases there is a great risk of intracranial bleeding (subdural or intra-cystic) after minor trauma. The origin of the bleeding is possibly related to rupture of delicate veins, tenuously adherent to the cyst capsule ${ }^{16,17}$. This has led some authors to indicate surgical treatment, even in the asymptomatic cases.

Surgical treatment is based in a craniotomy approach, resection of the cyst wall and wide communication with basal cisterns ${ }^{3}$. This technique has a $25 \%$ risk of recurrence of the cyst ${ }^{10}$. The 


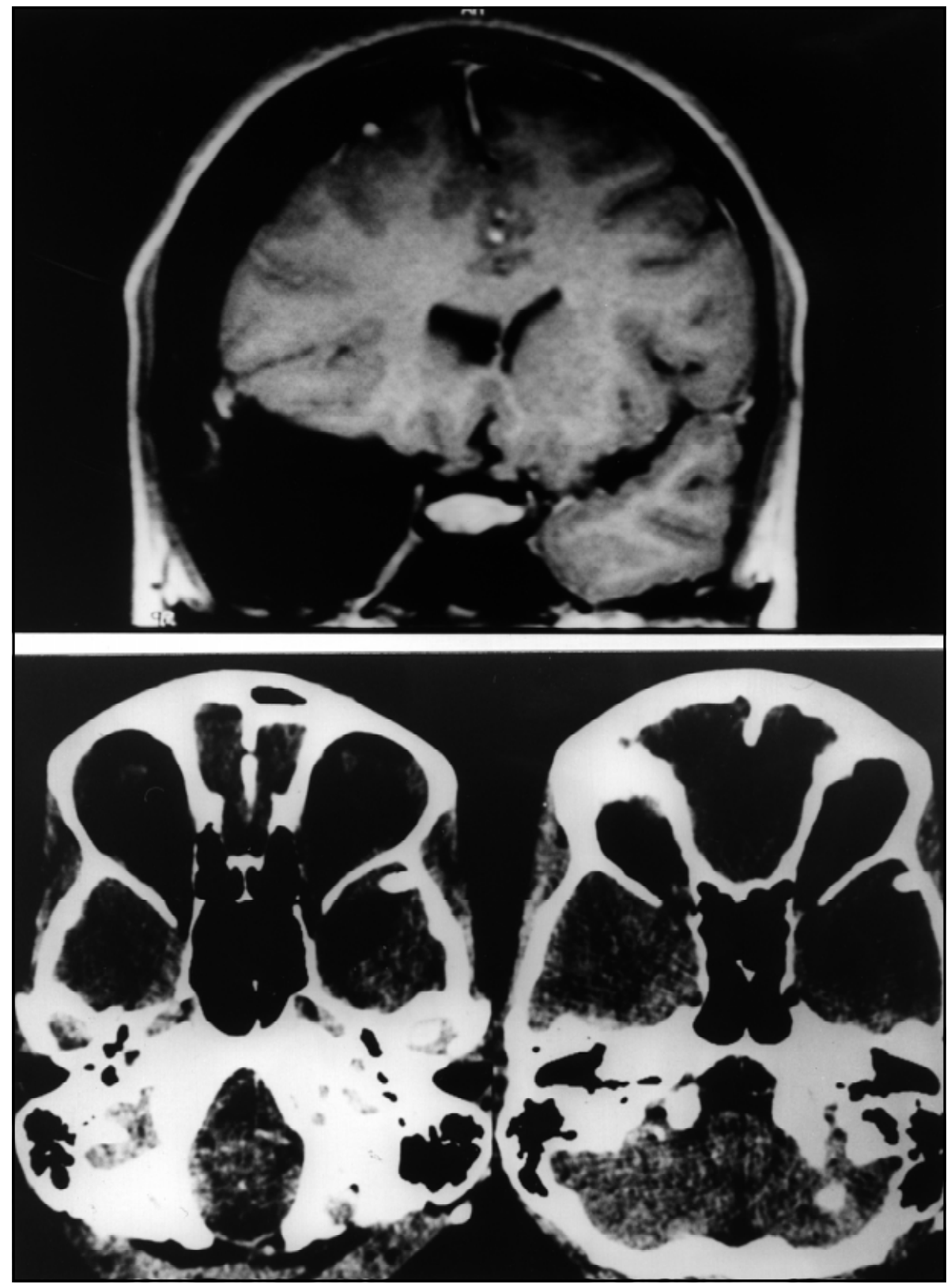

Fig 4 Above. A, coronal T1- weighted MRI shows a large left temporal cyst with subdural collection. Below, post-operative CT showing a normal image

indirect approach is performed via a cyst-peritoneal drainage and has the risk of poor function of the system or infection ${ }^{10}$. More recently some authors advocated a minimally invasive endoscopic approach to treat such cases ${ }^{18}$.

There are descriptions of bleeding and even death after surgical treatment of arachnoid cyst as well as in cases of chronic subdural hematomas ${ }^{3,19,20}$. Klintworth ${ }^{5}$ elegantly demonstrated, in an 
experimental work, that a fast decompression of a supratentorial lesion could cause bleeding in the brainstem and cerebellum. He attributed this to the fact of these structures being dislocated and under a process of ischemia, with reduction of blood flow. The fast decompression would lead to a great increase of blood flow, leading to bleeding. Modesti et al. ${ }^{20}$ reported seven cases of intracranial hematomas after drainage of extracerebral collections (5\% in their series). The etiology of this bleeding is not very clear. Some factors could contribute to its appearance: i) focal edema in the compressed brain; ii) reduction of venous return at the affected side; iii) subcortical swelling in the compressed area; iv) reduction of the regional blood flow in the ipsilateral hemisphere in cases of chronic subdural hematoma. More recently Spetzler ${ }^{21}$ and co-workers found evidence of loss of autoregulation and reactivity to $\mathrm{CO}_{2}$ in ischemic animal hemispheres. The chronic dilatation of the small vessels, in the presence of chronic ischemia, would lead to loss of autoregulation and resistance to normal perfusion pressure. The surgical decompression could cause edema and bleeding as it actually happened in our Case 1.

In conclusion, the surgical approach to the arachnoid cyst is technically simple and apparently without great complications. However, the presented cases confirm that the serious complications in the surgical treatment of big cysts with important midline shift lack special strategy to avoid adversities. Other cases, with severe compression to the midbrain structures, using cautious decompression, have an excellent clinical outcome and anatomical repositioning of the affected structures, indicating neuronal plasticity. Although most of the authors indicate a direct approach, we believe that in these cases a first approach through peritoneal drainage of the arachnoid cyst would permit a slower decompression of the intracranial structures and consequently readaptation of the microcirculation to the circumstantial perfusion pressure. Reevaluation of the clinical case would permit us, with persistence of symptoms, to use the direct approach, always taking into consideration serious complications.

\section{REFERENCES}

1. Zehnder M. Subarachnoidalsysten des Gehirns. Zbl Neurochir 1938;3:100-112.

2. Zuelch KJ. Betrachtungen ueber die Entstehung der fruekindlichen Hirnschaedel auf Grund der klinischen und morphologischen Befunde. Arch Kinderheilk 1954;149:1-27.

3. Borges G, Fernandes YB, Gallani NR: Hemorragia de tronco cerebral após remoção cirúrgica de cisto aracnóide da fissura silviana. Arq Neuropsiquiatr 1995;53:825-830.

4. Brito JCF, Gonçalves da Silva JA, Neves VD, Da Nobrega PV. Cisto aracnóideo intracraniano. Arq Neuropsiquiatr 1998;56:218-222.

5. Klintworth GK. The pathogenesis of secondary brainstem hemorrhage as studied in an experimental model. Am J Pathol 1965; 47:525-536.

6. Toennis W. Kongenitale zysten der Zisternen. Zbl Neurochir (Berlin) 1937;2:356.

7. Trowbridge WV, French JD. Benign arachnoid cysts of the posterior fossa. J Neurosurg 1952;9:398-404.

8. Zuelch KJ. Die arachnitis ( A. adhaesiva cystica ) In Handbuch der Neurochirurgie, Band III. Springer-Verlag, Berlin, Heidelberg, 1956;603-615.

9. Robinson RG. Congenital cysts of the brain: arachnoid malformation. Progr Neurol Surg 1971;4:133-174.

10. Di Rocco C. Arachnoid cysts. In Youmans JR. Neurological surgery. 3.Ed. Philadelphia: Saunders, 1990:1299-1325.

11. Stein SC. Intracranial developmental cysts of the middle cranial fossa. Neurosurgery 1981;8:647-650.

12. Rengachary SS, Watanabe I. Ultrastructure and pathogenesis of intracranial arachnoid cyst. J Neuropathol Exper Neurol 1981;40:61-83.

13. Yamakawa H, Ohkuma A, Hattori T, Niikawa S, Kobayashi H. Primary intracranial arachnoid cyst in the elderly: a survey on 39 cases. Acta Neurochir (Wien) 1991;113:42-47.

14. Dei-Anang, K. Klinik und Prognose der zerebralen Arachnoidalzysten, Inauguraldissertation. Mainz: Johannes Gutenberg Universitaet 1982.

15. Dei-Anang K, Borges G, Schuermann K, Ludwig B. Cerebral arachnoid cysts. Anais $20^{\circ}$ Congresso Latino Americano de Neurocirurgia São Paulo, 1983:74-75.

16. Markakis E, Heyer SL, Werry H. Die Aplasie der perisylvischen Region. Neurochirurgie (Stuttgart) 1980;22:211-220.

17. MC Cullough DC, Harbert JC, Manz HJ. Large arachnoid cyst at the cranial base. Neurosurgery 1980;6:76-81.

18. Schroeder HWS, Gaab M, Niendorf WR. Neuroendoscopic approach to arachnoid cysts. J Neurosurg 1996;85:293-298.

19. McKissock W. Subdural hematoma: a review of 389 cases. Lancet 1960;25:1365-1370.

20. Modesti L, Hodge CJ, Barmwell ML. Intracerebral hematoma after evacuation of chronic extracerebral fluid collections. Neurosurgery 1982;10:689-693.

21. Spetzler RF, Wilson CB, Weinstein P, Mehdorn M, Townsend J, Telle D. Normal perfusion pressure breakthrough theory. Clin Neurosurg 1977;25:651-672. 